\title{
Perspectives of clinician and biomedical scientists on interdisciplinary health research
}

\author{
Suzanne Laberge PhD, Mathieu Albert PhD, Brian D. Hodges MD PhD
}

Previously published at www.cmaj.ca

\section{ABSTRACT}

Background: Interdisciplinary health research is a priority of many funding agencies. We surveyed clinician and biomedical scientists about their views on the value and funding of interdisciplinary health research.

Methods: We conducted semistructured interviews with 31 biomedical and 30 clinician scientists. The scientists were selected from the 2000-2006 membership lists of peer-review committees of the Canadian Institutes of Health Research. We investigated respondents' perspectives on the assumption that collaboration across disciplines adds value to health research. We also investigated their perspectives on funding agencies' growing support of interdisciplinary research.

Results: The 61 respondents expressed a wide variety of perspectives on the value of interdisciplinary health research, ranging from full agreement (22) to complete disagreement (11) that it adds value; many presented qualified viewpoints (28). More than one-quarter viewed funding agencies' growing support of interdisciplinary research as appropriate. Most (44) felt that the level of support was unwarranted. Arguments included the belief that current support leads to the creation of artificial teams and that a top-down process of imposing interdisciplinary structures on teams constrains scientists' freedom. On both issues we found contrasting trends between the clinician and the biomedical scientists.

Interpretation: Despite having some positive views about the value of interdisciplinary research, scientists, especially biomedical scientists, expressed reservations about the growing support of interdisciplinary research.

$\mathrm{C}$ ollaboration between health disciplines is a new priority of research institutions and funding agencies. Many of these agencies have undergone restructuring and have developed programs specifically to intensify interdisciplinary research. In 2007, the US National Institutes of Health created 9 interdisciplinary research consortia "as a means of integrating aspects of different disciplines to address health challenges that have been resistant to traditional research approaches." In 2000, the Canadian Institutes of Health Research (CIHR) was established with an express mandate "to forge a health research agenda across disciplines, sectors, and regions that embraces scientific opportunity and reflects the emerging health needs of Canadians, the evolution of the health care system and the information needs of health policy decision-makers."

This change in priority has been attributed to 3 main fac- tors: the need to answer complex health problems, the need to explore questions that are not confined to a single discipline and the need to provide effective solutions to societal problems. ${ }^{3,4}$ Although the arguments advocating for interdisciplinary health research have evoked many kinds of promises, scientists undertaking collaborative research can also face many challenges. The past 10 years have seen a growing body of literature examining the impediments and facilitators to interdisciplinary collaboration. ${ }^{3,5-14}$

Despite this growing interest, little is known about scientists' opinions on the prevalent assumption that working across disciplines adds value to health research. Moreover, little consideration has been given to how scientists perceive the growing support of interdisciplinary research by funding agencies. In a survey commissioned by the CIHR, $36 \%$ of funded researchers indicated that their collaboration across disciplines had increased as a result of the agency's establishment. ${ }^{15}$ Whether this shift reflects researchers' scientific interests or their attempts to secure funding by appealing to the agency's policy of promoting interdisciplinary research is unknown.

As part of a broad research program investigating the integration of social science in health research, ${ }^{16}$ we conducted this study to examine to what extent, and why, biomedical and clinician scientists are for or against the promotion of interdisciplinary research. We targeted these types of scientists because they were predominantly affected by the move toward interdisciplinary research that occurred after the creation of the CIHR.

\section{Methods}

\section{Study design and participants}

We used a study design of descriptive qualitative content analysis based on semistructured interviews. This approach is appropriate for exploring a multidimensional, social and sensitive issue. It allows for an in-depth understanding of the variety of reasons that may ground a more or less favourable perspective concerning a critical question. Approval for the study design was received from the research ethics boards of the University Health Network and the Université de Montréal.

We recruited biomedical and clinician scientists who sit, or

From the Department of Kinesiology (Laberge), Université de Montréal, Montréal, Que.; and the Wilson Centre (Albert, Hodges), University of Toronto, Toronto, Ont.

Cite as CMAJ 2009. DOI:10.1503/cmaj.090661 
have sat, on CIHR peer-review committees. Biomedical scientists included laboratory and basic scientists, such as geneticists, biochemists and molecular biologists. Clinician scientists included physicians who carry out predominantly clinical research such as randomized controlled trials and clinical epidemiology. We sought participants with experience on peerreview committees because (a) they have evaluated various types of research projects in the health domain, and (b) they are in a position to exert influence on scientific activities.

We selected participants through purposeful sampling ${ }^{17}$ to include a variety of research areas, CIHR committees and university affiliations. We drew the sample from membership lists of CIHR peer-review committees, from the agency's inception in 2000 through to 2006 . We determined the number of participants to be interviewed using the saturation approach: new participants were added to our sample until no new themes were emerging. ${ }^{18}$ A preliminary analysis was thus conducted after each interview. The main characteristics of the sample are summarized in Table 1.

\section{Data collection}

We conducted interviews with 31 biomedical scientists and 30 clinician scientists. Because the participants were affiliated with universities across Canada, more than two-thirds were interviewed by telephone; the remainder were interviewed in person. Interviews were carried out by 2 team members (S.L. and M.A.). They lasted between 90 and 120 minutes and were audiorecorded with the participants' consent. These recordings were transcribed verbatim; NVivo 7 qualitative software was used to organize the data. ${ }^{19}$

The interview guide for our broad research program included more than 30 semistructured questions. We analyzed 2 themes in detail for this study: opinions concerning the assumed added value attributed to interdisciplinary research; and perceptions of the increasing support of interdisciplinary research by funding agencies. We did not prescribe a definition of interdisciplinary research because we were interested in how the participants would define it.

Table 1: Characteristics of 61 scientists who responded to a qualitative survey about interdisciplinary health research

\begin{tabular}{lcc}
\hline Characteristic & $\begin{array}{c}\text { Clinician } \\
\text { scientists } \\
n=30\end{array}$ & $\begin{array}{c}\text { Biomedical } \\
\text { scientists } \\
n=31\end{array}$ \\
\hline Sex & 23 & 18 \\
Male & 7 & 13 \\
Female & 17 & 17 \\
Academic rank & 10 & 13 \\
Professor & 3 & 1 \\
Associate professor & & $14(8-20)$ \\
Assistant professor & $20(15-27)$ & $4-31$ \\
\hline No. of years as faculty & $1-34$ & \\
Median (IQR) & & \\
Range & & \\
\hline
\end{tabular}

Note: $\mathrm{IQR}=$ interquartile range.

\section{Data analysis}

We used thematic content analysis to examine the data. ${ }^{20}$ First, preliminary coding categories were generated that reflected the various viewpoints expressed by the respondents. Second, we analyzed and coded the transcriptions of each interview based on these categories, which were refined when necessary. Third, we compared the categories (and subcategories) between the 2 groups of respondents. Two investigators (S.L. and M.A.) independently read and coded all of the interview transcriptions. Any differences in interpretation were discussed until a consensus was reached.

\section{Results}

Participants expressed a wide variety of perspectives on interdisciplinary research and its promotion by funding agencies. Opinions ranged from full agreement that interdisciplinary collaboration adds value to research (described below as an "affirmative viewpoint") to complete disagreement ("opposed viewpoint"). Many of the participants presented intermediate viewpoints, offering qualified perspectives on the assumed added value of interdisciplinary research. We divided respondents' perspectives on funding agencies' growing support for interdisciplinary research into 2 categories: one in which the level of support was seen as unwarranted, and one in which it was seen as appropriate. On both issues we found contrasting trends between the clinician and the biomedical scientists.

\section{Perspectives on the added value of interdisciplinary research}

\section{Affirmative viewpoint}

About one-third of the participants, most of whom were clinician scientists, felt that interdisciplinary research offers greater potential for understanding complex health problems (Table 2). When participants were asked to justify their favourable opinion, 3 themes emerged (Box 1). First, several participants said

Table 2: Respondents' viewpoints on interdisciplinary research and its promotion by funding agencies

\begin{tabular}{lccc}
\hline & $\begin{array}{c}\text { Clinician } \\
\text { scientists } \\
n=30\end{array}$ & $\begin{array}{c}\text { Biomedical } \\
\text { scientists } \\
n=31\end{array}$ & $\begin{array}{c}\text { Total } \\
n=61\end{array}$ \\
\hline Viewpoint & & & \\
\hline $\begin{array}{l}\text { On the prevalent assumption that } \\
\text { interdisciplinary collaboration } \\
\text { adds value to health research }\end{array}$ & 16 & 6 & 22 \\
$\quad \begin{array}{l}\text { Affirmative } \\
\quad \text { Qualified }\end{array}$ & 11 & 17 & 28 \\
$\begin{array}{l}\text { Opposed } \\
\text { On funding agencies' growing } \\
\text { support of interdisciplinary } \\
\text { research }\end{array}$ & 3 & 8 & 11 \\
$\begin{array}{l}\text { Level of support seen as } \\
\text { appropriate }\end{array}$ & 11 & & \\
\hline $\begin{array}{l}\text { Level of support seen as } \\
\text { unwarranted }\end{array}$ & 19 & 25 & 44 \\
\hline
\end{tabular}


Box 1: Sample quotes illustrating respondents' viewpoints on the prevalent assumption that interdisciplinary collaboration adds value to health research

\section{Affirmative}

Arguments affirming the added value of interdisciplinary research

Interdisciplinary research broadens understanding of the problem under study

Interdisciplinary research gives relevance to basic research

"Interdisciplinary research definitely enhances any work. I think it's always helpful to have the view of someone that comes from a different field. It brings research from one very narrow area into a broader perspective, and provides broader applications."

"If all the research of people is how to extract DNA from something and that's all they are learning, they probably think they don't have to understand policy issues. But they don't become researchers, they become technicians. If you are in the area of producing researchers for a publicly funded system, you need to understand that you are developing researchers to solve problems. I think interdisciplinary work shows the relevance of basic sciences."

Interdisciplinary research enables methodologic and instrumental progress

"We must work with people with a particular expertise with instrumentation or methodology that we are not expert in, if we want to make real advances. For instance, as a biochemist, I work with a bio-mathematician and a structural biologist. So together we're value added."

\section{Qualified}

Arguments supporting a qualified perspective on the assumed added value of interdisciplinary research

Science needs both disciplinary and interdisciplinary research

It depends on the nature of the question

It depends on the disciplines involved

It depends on the level of integration of the research team

It depends on the quality of the project more than its interdisciplinary nature

\section{Opposed}

Arguments challenging the assumed added value of interdisciplinary research

The advantages of interdisciplinary research have not been proven

Interdisciplinary research entails higher risk of failure

Interdisciplinary research is politically motivated provides the breadth." work if this is what it takes."
"Science benefits from both interdisciplinary and disciplinary research. Disciplinary research provides the depth and the interdisciplinary research

"I'm high on interdisciplinary research when it makes sense, depending on the problem. If you have a biological question, you answer it the best way you can, and it's not necessarily at the interface between disciplines. So the disciplinary approach might be the most expedient one, and that's the one that should be taken. The reverse may also be true: there are advantages in interdisciplinary

"I don't think there is room in health science for social scientists. I think it clouds the issue. I think the social science has rarely anything useful to say about science."

"The success of interdisciplinarity is very much determined by the harmony between interdisciplinary groups. There have been attempts to establish interdisciplinary research teams in the medical domain, but I don't know whether they work with an interdisciplinary approach, or they are only people extending their own individual research programs, but not really contributing as a whole."

"Interdisciplinary research is essential but whether it's of more heuristic value than disciplinary research, I can't say. I do interdisciplinary research but whether or not it enhances our knowledge, it all depends on the quality of the study. Sometimes what suffers is the quality of the research when there are multiple approaches."

"In medicine we have multidisciplinary approaches to particular diseases and it doesn't seem in my view to enhance necessarily our understanding of anything. I think we should always hold accountable people who articulate motherhood statements like: 'Interdisciplinary research enhances our understanding of phenomena.' Does it really? I don't know the answer, but I certainly wouldn't accept this statement. I think the onus is on people who want interdisciplinary research to demonstrate that it does enhance our understanding in some sort of scientific way. Are there examples of interdisciplinary groups that have contributed knowledge to more than a single discipline? I don't know. There's no evidence that one's better than the other. As a scientist I've learned not to believe anything, but to prove it."

"Interdisciplinary research is like venture capital. If it turns out to be valuable then it pays off big, but most of the time it turns out to be a deadly failure. Some particular combinations of disciplines really don't work. Somebody says: 'I think it's really important that we get a philosopher, a physicist and three cardiologists together on a team to do such and such.' ... I would really want to know a year or two years later how it's going. 'Have you done what you thought you were going to do?' And if you don't then the money dies."

"Interdisciplinarity is a good move politically; it's to please the government. Some say it will help to find solution to population health problems, but in my view putting all kinds of scientists together won't fix the problem any better than basic research could do." 
that interdisciplinary research offers greater understanding and broadens the application of scientific research. Many cited their personal experience in interdisciplinary research as a stimulating one: participants recalled how the integration of different perspectives brought new insights and enhanced the quality of their studies. Second, participants noted that interdisciplinary research strengthens the rationale for studies and allows basic scientists to appreciate how their highly specialized research is related to broader clinical or socio-economic issues. The third theme, predominant among the biomedical scientists, referred to methodologic and instrumental collaboration. Respondents described examples in which knowledge from one discipline was used instrumentally to carry out research in their own discipline. Drawing on their personal experience, they underscored the advances in knowledge enabled by collaborative work with experts outside of the health domain, such as engineers, physicists and bio-informatics/genomics specialists.

\section{Qualified viewpoint}

Most participants, and a large proportion of biomedical scientists (Table 2), expressed qualified support for the added value of interdisciplinary research. This viewpoint was supported by a number of different arguments (Box 1). Above all, most respondents stressed that disciplinary research is just as valuable as interdisciplinary research: these modes of inquiry are seen as complementary, with disciplinary research providing indispensable depth and interdisciplinary research providing necessary breadth.

Participants also emphasized that the added value of interdisciplinary research is contingent upon a number of characteristics of the project, including the nature of the research problem, the disciplines involved, the level of integration among the disciplines and the overall quality of the research practice (Box 1). For example, participants felt that interdisciplinary research would be more relevant for addressing complex health problems in the population, whereas a disciplinary approach would be more efficient for understanding disease mechanisms. The epistemological or methodologic distance of the disciplines involved was another frequently mentioned issue. For instance, some commented that a joint venture involving basic and social sciences would be less fertile than one involving diverse basic sciences. Some participants were skeptical that a genuine integration of various disciplines is really achieved in many interdisciplinary teams; poor integration reduces the scientific power of interdisciplinary research. Finally, some respondents were dubious about the scientific quality of this new mode of inquiry. Although they recognized the value of interdisciplinary research, they believed that the combination of multiple approaches can be detrimental to scientific quality. The quality of research, rather than its interdisciplinary nature, would be the best guarantee of advancing knowledge.

\section{Opposed viewpoint}

Although they were a minority, some participants, predominantly biomedical scientists (Table 2), clearly opposed the assumption that interdisciplinary research is valuable. Three main points were raised by these participants (Box 1). First, invoking a scientific rationale, some claimed that the burden of proof should lie with interdisciplinary research to provide evidence that its results are valuable. Participants noted that they have never seen a rigorous scientific study comparing interdisciplinary and disciplinary research outcomes. Second, looking at the emerging teams currently burgeoning in the health domain, some believed that the combination of highly disparate disciplines represents a high risk, especially because most scientists have very specialized backgrounds and they have not been trained to work according to an interdisciplinary approach. Third, some participants felt that the added value of interdisciplinary research relates more to marketing and the public image of science than to the advancement of knowledge per se.

\section{Perception of funding agencies' growing support of interdisciplinary research}

\section{Level of support is appropriate}

Some participants felt that the current level of support of interdisciplinary research is appropriate (Box 2). These participants noted that increased funding offers a warranted "catch up" for a previously underfunded type of research. Hence, it allows for a more adequate balance between disciplinary and interdisciplinary research. Some participants felt that, although the funding agencies' promotion of interdisciplinary research represents a challenge for them, they see it as an opportunity to experience new ways of doing research or to foster an open-mindedness among health scientists. Contrary to other participants, these respondents believed the benefits of interdisciplinary research exceed the risks.

\section{Level of support is unwarranted}

The vast majority of participants (44 of 61) felt that the funding agencies' increasing level of support of interdisciplinary research was in some way unwarranted (Table 2). This unfavourable perception was predominant in both groups more so among the biomedical scientists.

A wide range of arguments were raised in critique of funding agencies' strong promotion of interdisciplinary research, and some participants mentioned more than one argument. We classified these arguments into 2 broad categories: processcentred and outcome-centred arguments (Box 2).

Process-centred arguments: Two interrelated process-centred arguments were most recurrent. One was that funding agencies' emphasis on supporting interdisciplinary research leads to the creation of artificial teams. The other was that a top-down process of imposing interdisciplinary structures on teams constrains scientists' freedom and therefore threatens the quality of their work. The limited resources available for research encourage investigators to orient their project to meet explicit funding criteria. The establishment of a substantial number of granting programs dedicated to interdisciplinary research thus creates a pressure on scientists to recruit people of various disciplines on their team, even if they do not work together in a genuinely integrative manner. Participants spoke at length about this concern and claimed that interdisciplinary research should not be 
Box 2: Sample quotes illustrating respondents' perceptions on funding agencies' growing support of interdisciplinary research

\section{Level of support is appropriate}

Support of interdisciplinary research allows for a better balance between interdisciplinary and disciplinary research

Support of interdisciplinary research is an opportunity to develop researchers' open-mindedness

The risks of interdisciplinary research are low relative to the potential benefits

\section{Level of support is unwarranted}

\section{Process-centred arguments}

Current support for interdisciplinary research leads to the creation of artificial teams

Interdisciplinary research should be investigator-driven, not mandated

Funding agencies define interdisciplinary research too strictly

Interdisciplinary research is counter-productive

Funding levels do not support effective interdisciplinary research

\section{Outcome-centred arguments}

Current emphasis on interdisciplinary research is detrimental to disciplinary research

Current emphasis on interdisciplinary research is detrimental to excellence in knowledge production

Current emphasis on interdisciplinary research impedes researchers' creativity
"Right now what they're trying to do is to promote, and allow for a catch-up of the areas that are interdisciplinary because they have traditionally been under funded or completely unfunded. So, the current promotion may be justifiable."

"Interdisciplinarity helps disciplinary scientists to broaden their horizons. I think that when a biomedical scientist sees how his or her research contributes to population health, his perspective on his own work changes. If junior scientists can be exposed to interdisciplinary research early in their career, they may develop a different way of thinking about research and a different way of asking research questions."

"I think that the risk-benefit ratio of interdisciplinary research is very low and that the benefit-risk ratio is very high because what you have to gain from interdisciplinary research is very important. Hence, you need the leverage, especially when resources are so limited. We have to collaborate, we have to go interdisciplinary and there should be resources to encourage it."

"ClHR [Canadian Institutes of Health Research] has forced interdisciplinary research and in many cases it's artificial; people are recruiting researchers of different flavors just to meet the rules to apply for funding. That kind of interdisciplinary research is of little value in most cases."

"Even though I think there are some cases where interdisciplinary research is very important, what I have concerns about is the fact that the funding agencies seem to be pushing it for its own sake. I think it should come from the bottom up and not from the top down."

"The problem is the way interdisciplinary research is defined at the CIHR. Interdisciplinary means involving the social sciences, policy, legality, those sorts of areas in projects. It's not accepted that interdisciplinary research could involve collaboration between people from the basic sciences. I'm working with people across multiple disciplines in the basic sciences. I don't go to the psychologists or the sociologists to see if they would like to be involved because it's not relevant to the type of questions I'm asking. So it's harder to get funded."

"I think overall interdisciplinary research is counter-productive. It costs more money, it makes thing more complicated, it doesn't bring anything particularly valuable from a scientific point of view."

"[The] funding is usually far too low [for interdisciplinary work] to effectively take place. So, the money gets spread very thin, and I can see why people would object to trying to put together these somewhat artificially created teams, if there's not really enough funding to support what all these different players would do."

"I'm concerned about this strong promotion for interdisciplinary research because it's at the expense of disciplinary research. Very highly skilled investigators are now being shut out because of that. Interdisciplinary research has sort of become a bandwagon. I'm not sure the quality of the research is the same. I think we leaned toward interdisciplinary at the expense of highly rigorous disciplinary research."

"I find that the interdisciplinary research is just not of the same quality as disciplinary research because there are a lot of forced interactions to meet the criteria of the funding agencies. It's not good for the scientists and knowledge production. I'm unclear whether that strategy will win us Nobel Prizes."

"Interdisciplinary research is currently imposed on all research domains. This is very annoying and everyone is dissatisfied with that. I think it will greatly constrain creativity. Funded research should first and foremost be a tool for fostering creativity. I think that forcing people to work together who wouldn't have otherwise could be detrimental to creativity. Currently it seems to me that scientists are teaming up for the sole sake of getting funded to pursue their work." 
mandated by the funding agencies but should rather be investigator-driven. It should evolve naturally according to the issues the investigator considers to be critical for the advancement of knowledge. The research could involve scientists of different fields, with these scientists being recruited essentially to better grasp the complexity of the problem under study.

Participants' comments also included 3 other processcentred arguments (Box 2). Some pointed to the "too strict" CIHR definition of interdisciplinary research, which encourages research teams to include collaboration across 4 "pillars" of health research (biomedical sciences; clinical sciences; health systems and services; and social, cultural, environmental and population health). This was judged to be too constraining and difficult to achieve in many contexts. Other participants felt that interdisciplinary research is counterproductive because it requires considerable human and financial resources and is more difficult to manage, such that the knowledge generated is not proportional to the investment. Finally, the funding level granted to interdisciplinary research teams was judged to be too low given the number of investigators involved. Hence participants saw the funding agencies' promotion of interdisciplinary research as inappropriate given current budget constraints.

Outcome-centred arguments: Three main themes relating to outcomes emerged from the participants' unfavourable comments (Box 2). One referred to the prejudicial impact on disciplinary research. Participants felt that highly skilled investigators not involved in interdisciplinary teams are deprived of grants because of the funding agencies' emphasis on interdisciplinary research. Hence, advancements of knowledge in disciplinary research were thought to be jeopardized.

A second argument offered by some respondents was that interdisciplinary research is not of the same scientific quality as disciplinary research, in part because of the often artificial nature of the teams.

The third argument was that the emphasis on interdisciplinary research impedes the creativity of scientists. Some participants believed that funding agencies' influence on the research agenda becomes detrimental to free and innovative thinking.

\section{Relation between perceived value of interdisciplinary research and funding agencies' support}

Logically, one might assume that participants who agreed that interdisciplinary collaboration adds value to health research would also consider funding agencies' initiatives to encourage interdisciplinary research appropriate. Surprisingly, we found that half of the respondents who agreed that interdisciplinary research adds value also perceived the growing support by funding agencies to be unwarranted (Table 3). Hence, a positive attitude toward interdisciplinary research did not necessarily imply endorsement of funding agencies' research agenda. Moreover, a vast majority (22 of 28) of the participants who provided a qualified viewpoint on the value of interdisciplinary research considered the current level of support by funding agencies to be excessive. Not surprisingly, all of the respondents who felt that interdisciplinary research does not add value to health research also perceived the growing support by funding agencies to be unwarranted.

\section{Interpretation}

We found a wide range of views among health scientists concerning the prevalent assumption that collaboration across disciplines adds value to health research. Favourable views echoed the arguments put forward by promoters of interdisciplinary research. ${ }^{1-3,8,21-23}$ For example, participants affirmed the belief that interdisciplinary research facilitates better understanding of complex health problems, adds social or ethical relevance to basic research and enables scientific progress through methodologic and instrumental collaboration.

Those expressing a qualified viewpoint emphasized that interdisciplinary research was valuable in addition to, but not in place of, disciplinary research. They also cautioned that the value of research lies in its scientific quality, independent of its disciplinary or interdisciplinary mode of inquiry. Various factors that can affect the value of interdisciplinary research were addressed. Some echoed factors identified in previous studies, such as the relevance of the disciplinary perspectives to the topic of investigation, ${ }^{4,7,12,24}$ the epistemological distance between the disciplines involved, ${ }^{16,25,26}$ and the integration of the research team..$^{5,11-13,25,27-29}$

Although they were a minority, some participants (mostly biomedical scientists) challenged the presumption that interdisciplinary research is a valuable approach. They claimed that evidence is required to support this conclusion and that interdisciplinary work represents a higher risk of failure. Some of their skepticism was rooted in the confusion about "what interdisciplinarity is." This bewilderment confirms findings of previous studies showing that the distinction between "pluri-," "trans-," "multi-" and "cross-"disciplinarity is blurred for most scientists. ${ }^{3,4,7,30,31}$

Our study offers 4 main contributions to the literature on interdisciplinary research. First, we have documented health scientists' negative attitudes toward funding agencies' growing support of interdisciplinary research, even among participants who agreed that collaboration across disciplines adds value to health research. Second, we have identified key sources of the negative attitudes: the creation of artificial teams because of funding agencies' emphasis on supporting interdisciplinary research; and the top-down process considered to be detrimental to scientists' freedom. The latter echoes some debate about scientists' freedom and the tensions with granting institutions. ${ }^{32-36}$ To what extent should interdisciplinary research be policy-driven or investigatordriven? This question needs to be explicitly addressed by all stakeholders involved in health research.

A third contribution of our study is the observation that disin-

Table 3: Perspective on whether interdisciplinary collaboration adds value to research, according to perspective on funding agencies' growing support of interdisciplinary research

\begin{tabular}{lcc}
\hline $\begin{array}{l}\text { Perspective on } \\
\text { added value }\end{array}$ & $\begin{array}{c}\text { Level of support } \\
\text { seen as appropriate } \\
n=17\end{array}$ & $\begin{array}{c}\text { Level of support seen } \\
\text { as unwarranted } \\
n=44\end{array}$ \\
\hline Affirmative & 11 & 11 \\
Qualified & 6 & 22 \\
Opposed & - & 11 \\
\hline
\end{tabular}


centives to undertake interdisciplinary research not only relate to the practicalities or quality of the relationships between team members, as highlighted by numerous studies, ${ }^{5-7,9-14,27-29}$ but also to skepticism regarding its outcomes and scientific quality. Although the potential of interdisciplinary research may be considerable, we cannot ignore that integrating different epistemologies, methodologies and paradigms is challenging and may be irrelevant for answering some research questions.

A fourth contribution of this study is that it highlights different trends in viewpoints between biomedical and clinician scientists. The latter group was more inclined than the former to value interdisciplinary research and view its promotion by funding agencies as justified. This can be linked to the different kind of problems, professional environments and stakes facing these 2 groups of scientists. This reiterates the question: Is interdisciplinary research equally appropriate to the diverse questions addressed by health researchers?

\section{Limitations}

Our study has some limitations. We included only 2 types of scientists. Also, we limited participants to members of CIHR peer-review committees. Hence, the transferability of findings may be limited. Further investigation on the views of health services scientists and social scientists is needed because their research practice is different.

\section{Conclusion}

Despite having some positive views about the value of interdisciplinary research, scientists, especially biomedical scientists, expressed reservations about funding agencies' level of support of such research. Our findings suggest that, if the support is to be maintained or increased, efforts should be made to provide convincing evidence of its added value for tackling complex health problems. The valuation of interdisciplinary research should be sensitive to the unique context of each research problem. Furthermore, measures should be taken to avoid the undesired effects of funder-driven interdisciplinary research, such as the creation of artificial teams.

\section{This article has been peer reviewed.}

\section{Competing interests: None declared.}

Contributors: All of the authors contributed to the conception and design of the study. Mathieu Albert and Suzanne Laberge collected the data, and all of the authors contributed to the analysis and interpretation of the data. Suzanne Laberge drafted the article. Brian Hodges and Mathieu Albert revised it critically. All of the authors approved the final version submitted for publication.

Acknowledgement: The authors thank the biomedical and clinician scientists who participated in the study for giving their time for the interview.

Funding: This study was supported by the Canadian Institutes of Health Research (CIHR) grant no. KTE-72140. The CIHR played no role in the analysis or interpretation of the data or in the decision to submit the manuscript for publication.

\section{REFERENCES}

1. National Institutes of Health. NIH launches interdisciplinary research consortia. Washington (DC): The Institues; 2007. Available: http://nih.gov/news/pr/sep2007 /od-06.htm (accessed 2009 Aug. 26).
2. Canadian Institutes of Health Research. About the institutes. Ottawa (ON): The Institutes; 2007. Available: www.cihr-irsc.gc.ca/e/7155.html (accessed 2009 Oct. 5).

3. Committee on Facilitating Interdisciplinary Research, Committee on Science, Engineering, and Public Policy; National Academy of Sciences, National Academy of Engineering, Institute of Medicine. Facilitating interdisciplinary research. Washington (DC): The National Academies Press; 2004.

4. Choi BCK, Pak AWP. Multidisciplinarity, interdisciplinarity and transdisciplinarity in health research, services, education and policy: 1. Definitions, objectives, and evidence of effectiveness. Clin Invest Med 2006;29:351-64.

5. Nair KM, Dolovich L, Brazil K, et al. It's all about relationships: a qualitative study of health researchers' perspectives of conducting interdisciplinary health research. BMC Health Serv Res 2008;8:110-20.

6. Choi BCK, Pak AWP. Multidisciplinarity, interdisciplinarity and transdisciplinarity in health research, services, education and policy: 2. Promotors, barriers, and strategies of enhancement. Clin Invest Med 2007;30:E224-32.

7. Smith PM. A transdisciplinary approach to research on work and health: What is it, what could it contribute, and what are the challenges? Crit Public Health 2007;17:159-69.

8. Hall JG, Bainbridge L, Buchan A, et al. A meeting of minds: interdisciplinary research in the health sciences in Canada. CMAJ 2006;175:763-71.

9. Campbell LM. Overcoming obstacles to interdisciplinary research. Conserv Biol 2005;19:574-7.

10. Lynch J. It's not easy being interdisciplinary. Int J Epidemiol 2006;35:1119-22.

11. Sharachchandra L, Norgaard RB. Practising interdisciplinarity. Bioscience 2005; 55:967-75.

12. Giacomini M. Interdisciplinary in health services research: dreams and nightmares, maladies and remedies. J Health Serv Res Policy 2004;9:177-83.

13. McCarthy J. Tackling the challenges of interdisciplinary bioscience. Nat Rev Mol Cell Bio 2004;5:933-7.

14. Aagaard-Hansen J, Ouma JH. Managing interdisciplinary health-researchtheoretical and practical aspects. Int J Health Plann Manage 2002;17:195-212.

15. EKOS Research Associates. Canadian Institutes of Health Research: survey of funded and non-funded researchers. Executive summary. Ottawa (ON): The Associates; 2006. Available: www.cihr-irsc.gc.ca/e/documents/executive_summary _researcher_survey_e.pdf (accessed 2009 Aug. 26).

16. Albert M, Laberge S, Hodges BD, et al. Biomedical scientists' perception of the social sciences in health research. Soc Sci Med 2008;66:2520-31

17. Creswell JW. Qualitative inquiry and research design. Thousand Oaks (CA): Sage Publications; 1998.

18. Strauss AJC, Corbin J. Basics of qualitative research. Techniques and procedures for developing grounded theory. Thousand Oaks (CA): Sage Publications; 1998.

19. Bazeley P. Qualitative data analysis with NVivo. Thousand Oaks (CA): Sage Publications; 2007.

20. Neuendorf KA. The content analysis guidebook. Thousand Oaks (CA): Sage Publications; 2002.

21. Armstrong PW. Advancing interdisciplinary health research: a synergism not to be denied. CMAJ 2006;175:761-2.

22. De Melo-Martin I. Creating reflective spaces. Interactions between philosopher and biomedical scientists. Perspect Biol Med 2009;52:39-47.

23. Whitfield J. An indifference to boundaries. Nature 2008;451:872-3.

24. Wickson F, Carew AL, Russell AW. Transdisciplinary research: characteristics, quandaries and quality. Futures 2006;38:1046-59.

25. Bachrach CA, Abeles RP. Social science and health research: growth at the National Institutes of Health. Am J Public Health 2004;94:22-8.

26. Choi BCK, Pak AWP. Multidisciplinarity, interdisciplinarity and transdisciplinarity in health research, services, education and policy: 3. Discipline, inter-discipline distance, and selection of discipline. Clin Invest Med 2008;31:E41-8.

27. Jeffrey P. Smoothing the waters. Observations on the process of cross-disciplinary research collaboration. Soc Stud Sci 2003;33:539-62.

28. Cummings JN, Kiesler S. Collaborative research across disciplinary and organizational boundaries. Soc Stud Sci 2005;35:703-22.

29. Dowling B, Powell M, Glendinning C. Conceptualising successful partnerships. Health Soc Care Community 2004;12:309-17.

30. Aboelela SW, Larson E, Bakken S, et al. Defining interdisciplinary research: conclusions from a critical review of the literature. Health Serv Res 2007:42:329-46.

31. Whitfield K, Reid C. Assumptions, ambiguities, and possibilities in interdisciplinary population health research. Can J Public Health 2004;95:434-6.

32. Bennich-Björkman L. Has academic freedom survived? An interview study of the conditions for researchers in an era of paradigmatic change. High Educ Q 2007:61:334-61.

33. Maasen S, Oliver L. Transdisciplinarity: A new mode of governing science? Sci Public Policy 2006;33:399-410.

34. Kogan M. Modes of knowledge and patterns of power. High Educ 2005;49:9-30.

35. Choi BCK, Pang T, Lin V, et al. Can scientists and policy makers work together? $J$ Epidemiol Community Health 2005;59:632-7.

36. Nathan DG, Weatherall DJ. Academic freedom in clinical research. $N$ Engl J Med 2002;347:1368-71

Correspondence to: Dr. Suzanne Laberge, Département de Kinésiologie, Université de Montréal, CP 6128, succ. Centre-ville, Montréal QC H3C 3J7; fax 514 343-2181;

suzanne.laberge@umontreal.ca 